for surveying purposes are shown by Messrs. Barr and Stroud.

A small model Hilger interferometer for the correction of prisms and lenses is fitted up to show the optical imperfection of a piece of glass, and a strain viewer by the same makers is arranged to show strain in a glass tumbler. In addition to a spectrographic outfit for metallurgical analysis, Messrs. Adam Hilger are exhibiting an outfit for spectrophotometry in the ultra-violet region of the spectrum. Messrs. Bellingham and Stanley also are showing a spectro-photometry outfit. This apparatus assumes a special interest just now in connexion with the spectral test employed by Dr. Bendien in his experiments on cancer diagnosis. This consists of a spectrograph with quartz optical elements, and a photometer of the sector type driven by an electric motor; the photometer design is based partly on the suggestions recently made by H. J. McNicholas in the Bureau of Standards Journal of Research, vol. 1, pp. 942-949. Albsorption measurements are obtained by taking a number of exposures, each with a different opening of the variable sector. On the resulting photograph, positions are found in each spectrum where the amount of light passing through the tube of solution is equal to that passed by the variable sector, and from the data obtained an accurate absorption curve can be obtained. Polarimeters for use in the visible and ultraviolet are shown by both these makers.

A rangefinder by Messrs. Barr and Stroud, specially adapted for short ranges in the Museum, is fitted up for demonstration. The internal construction of a rangefinder and various optical parts used in the construction are also shown.

Price catalogues of the instruments in the exhibition are available to the public.

The exhibition is on view during the normal opening hours of the Museum, namely, Mondays, Tuesdays, Wednesdays, Fridays, 10 A.M. to 6 P.M.; Thursdays and Saturdays, 10 A.M. to 10 P.M.; Sundays, 2.30 P.M. to 6 P.M.

\section{Evolutionary Tendencies in the Jaws and Teeth.}

$\mathrm{D}^{\mathrm{C}}$

URING the recent International Orthodontic Congress in London, Prof. Elliot Smith delivered an address on "Evolutionary Tendencies in the Jaws and Teeth". He pointed out that, in the human child, there is a delay of four years after the milk teeth have erupted before the permanent teeth commence to appear, and a further ten to fifteen years are required to complete its dental equipment. Up to the seventh year, that is, during the pause between milk and permanent teeth, the child is growing a very large brain, and, again, for a further period of fifteen years or so, when his dental affairs are relatively sluggish, he is learning how to put his complicated cerebral equipment to its fullest biological uses. During this period he develops a chin, because the growth of the tooth-bearing part is restrained by the long delay in the eruption of his teeth. The delay in tooth and jaw development is undoubtedly due to the growth of the brain and the subsequent development of its full functions, which disturbs the orderly process of uniform growth of the jaws and eruption of teeth.

In the apes, the process of eruption of the second teeth follows more closely on that of the first teeth; the second permanent molars erupt before the deciduous molars are replaced by the premolars. Dr. Degerøl, of Copenhagen, has recently pointed out that, in Neanderthal man, the simian type of sequence was still retained in the eruption of his teeth. There are reasons for inferring that the defective chin development of Neanderthal man may be associated with this fact-that the precocious cutting of his teeth permitted the tooth-bearing part of the jaw to keep pace more nearly with the growth of the rest of the jaw and preclude the development of a chin.

In the evolution of man from his simian ancestors the two fundamental structural advances were the great growth of the brain and the changes in the facial region culminating in the development of a chin. To the consequences of these evolutionary changes must be ascribed the origin of the problems of orthodontia. There is no just reason for the belief that the reduction or absence of the third molar is a sign of the early disappearance of this tooth in the human species, or that dental troubles, such as crowding and displacement of teeth, are due to evolutionary changes now active.

\section{University and Educational Intelligence.}

Cambridge.-At St. John's College the following research exhibitions have been awarded: for biochemistry, M. C. Franklin, Canterbury Agricultural College; for experimental physics, R. H. Sloane, Queen's University, Belfast.

The City and Guilds of London Institute gives prominence in its report for 1930 to the work of the South London Technical Art School established at Kennington in 1879 for training persons engaged in the art industries of the locality, which were chiefly modelling from terra cotta, and for the study of architectural decoration. The school occupies a unique and useful place and has trained the majority of the leading sculptors and some of the foremost painters in Great Britain. The Engineering College was attended by 522 students, a larger number than in any of the four preceding years, and the number of first-year diploma and undergraduate students and of special and post-graduate students was larger than in any year since before the War. The number of candidates examined at the Institute's technological examinations in Great Britain and Ireland and overseas (chiefly in India and Ceylon and New Zealand) increased, respectively, to 14,721 (more than in any year since the War) and 1608 .

Some trends in recent scientific research in Americe are reflected in statistics of the doctorates conferred in the sciences in American universities. These have been tabulated year by year since 1919 by the National Research Council, the annual bulletin of which on the subject constitutes a useful index to the relevant theses. The total number of these doctorates has increased every year, rising from 336 in 1921 to 1055 in 1930. Of the subjects of the 1055 theses on which science doctorates were conferred last year, about one-third are, as usual, in the field of chemistry. Next comes zoology with 100. Psychology has dropped from 112 to 92 and physics from 101 to 89 . All previous records were broken in botany (81) mathematics (74), geology (63-previous record 45), engineering (49), physiology (46), geography (17), whilst the following universities conferred more science doctorate than they have ever done before: Wisconsin (86), Cornell (80), Michigan (55), Ohio State (50), Massachusetts Institute of Technology (29), Pittsburg (15), Virginia (12), Indiana (11) Kansas (11). 